\title{
Fabrication and Evaluation of a 2000V-4A SiC Module
}

\author{
Xing $\mathrm{Hu}^{1}$, Ao Liu ${ }^{1}$, Gang Chen ${ }^{1,2}$, \\ ${ }^{1}$ Nanjing Electronic Device Institute, Nanjing, 210016, China \\ ${ }^{2}$ State Key laboratory of Wide-bandgap Semiconductor Power Electronics, Nanjing, China
}

Keywords: $4 \mathrm{H}-\mathrm{SiC}$; high temperature; reverse recovery; surge current

Abstract. A new 2000V-4A Junction Barrier controlled Schottky (JBS) diodes module has been fabricated using $4 \mathrm{H}-\mathrm{SiC}$. The module is composed of two SiC JBS diodes, and it is used for rectifying circuits. By adopting the proper SBD metal ,optimized structures and fabrication process, we succeeded in achieving good balance between blocking voltage and on-resistance, especially at high temperature to $175^{\circ} \mathrm{C}$. Furthermore, the fabricated module have a fast recovery time of 26ns, and diodes of the module can withstand the surge current of $20 \mathrm{~A}$.

\section{Introduction}

Silicon Carbide(SiC) are wide-bandgap (WBG) semiconductors theoretically having the best properties (critical electric field, mobility and intrinsic concentration) for power electronics applications[1]. Its superior mechanical and electrical characteristics confer them to be the most adequate candidates for manufacturing of high power and high temperature electronics. Since silicon carbide is able to operate at high temperatures, cooling equipment would become much simpler in application of high temperature power electronics[2]. SiC devices are in theory able to operate at condition of large current and high frequency. This paper describes the design and the fabrication of high power module made up by two 4H-SiC JBS diodes, which blocking voltage is $2 \mathrm{kV}$ and current rating is $4 \mathrm{~A}$. Then, a detailed investigation of the on-state characteristics, leakage current, surge current and switching characteristics of the module are presented.

\section{Fabrication of $4 \mathbf{H}-\mathrm{SiC}$ diodes}

The module is composed of two 2000V2A diodes .The 2000V2A 4H-SiC diodes are designed as junction-barrier Schottky(JBS) structures in which Schottky regions alternate with local implanted p-type regions[3]. In the forward direction, current flows through the Schottky regions, characteristics of the schottky contact determins the resistance of the diode. Meanwhile, the gap between the p-type regions is made so narrow that, when a diode is connected in the reverse direction, space-charge regions of neighboring $p-n$ junctions merge at a certain voltage. Compared with ordinary Schottky diodes, the region of the highest field in a diode with a JBS structure is somewhat shifted away from the surface into the bulk, which leads to a decrease in the reverse current.

The cross section view of a diode chip is shown in Fig.1. A guard system of guard rings, which formed by the implantation with different concentration of $\mathrm{Al}$ ions introduced into the n-layer at room temperature, served to suppress early edge breakdown in the diode structure. The post-implantation annealing was performed at $1650^{\circ} \mathrm{C}$ in the atmosphere of argon for $30 \mathrm{~min}$.An ohmic contact is formed on the backside of the structure by thermal evaporation of nickel, with the subsequent annealing at $1000{ }^{\circ} \mathrm{C}$ for $5 \mathrm{~min}$. A $2 \mathrm{~mm} * 2 \mathrm{~mm}$ Schottky contact is formed on the surface of the epi-layer by vacuum evaporation of titanium, with the subsequent annealing in vacuum at $500{ }^{\circ} \mathrm{C}$ for $10 \mathrm{~min}$. On the frontside of the wafer, nickel was evaporated, covered by electroplated $\mathrm{Ag}$ of $4 \mathrm{um}$. $\mathrm{SiO}_{2}$ was deposited for protection by PECVD. On the backside of the wafer, $\mathrm{Ti} / \mathrm{Ni} / \mathrm{Ag}$ was fomed was formed by electroplating. At last, two chips are packaged in a module(Fig.2). The surface of the chip is covered by silicone . 


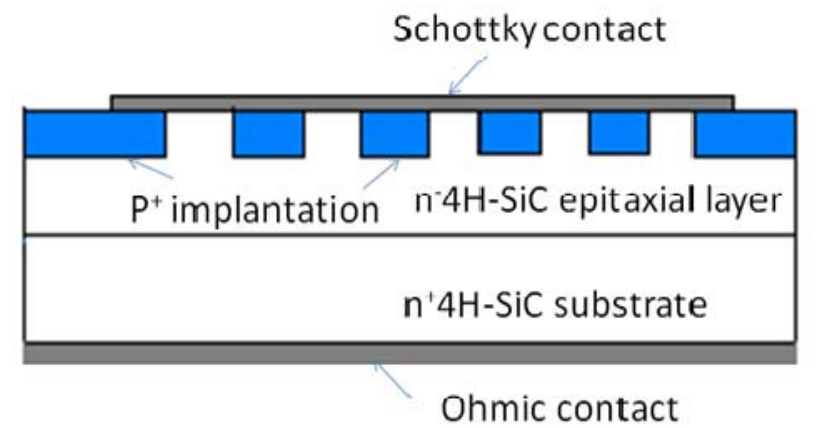

Fig. 1 Schematic cross section view of 4H-SiC JBS diodes

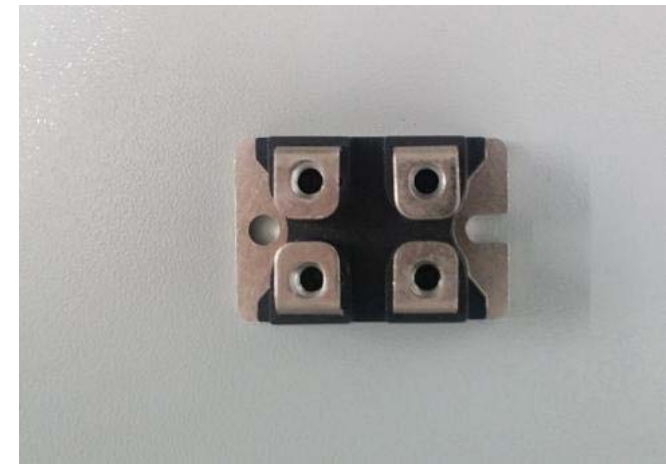

Fig.2 Two diodes packaged in the module

\section{Reverse Characteristics}

Fig. 3 shows the reverse $\mathrm{I}-\mathrm{V}$ characteristics of the fabricated $4 \mathrm{H}-\mathrm{SiC}$ module. We have obtained capable of blocking more than $2 \mathrm{kV}$. Measurements of the reverse characteristics were carried out by Tektronix 370B. In order to acquire the characteristics of diodes under high temperatures, we use a heating device to heat diodes. The reverse I-V characteristic was obtained at different temperatures at $25^{\circ} \mathrm{C}$ and $175^{\circ} \mathrm{C}($ Fig.4). The leakage current increases with temperature, but it is still as low as less than $50 \mu \mathrm{A}$ at $175^{\circ} \mathrm{C}$. At temperature $175^{\circ} \mathrm{C}$, leakage current was $20 \mathrm{uA}$ at $2000 \mathrm{~V}$. However, this leakage level did not affect breakdown characteristics.

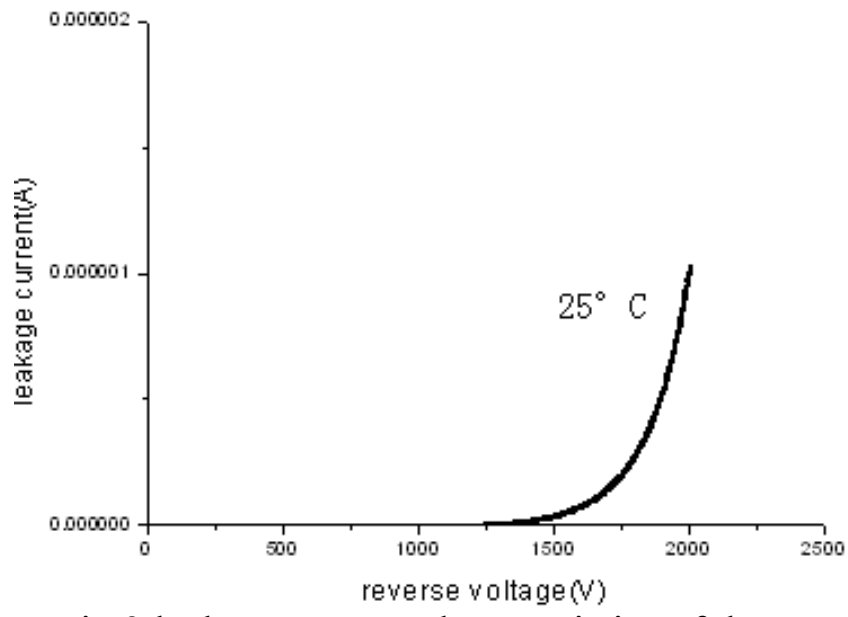

Fig.3 leakage current characteristics of the fabricated module at $25^{\circ} \mathrm{C}$

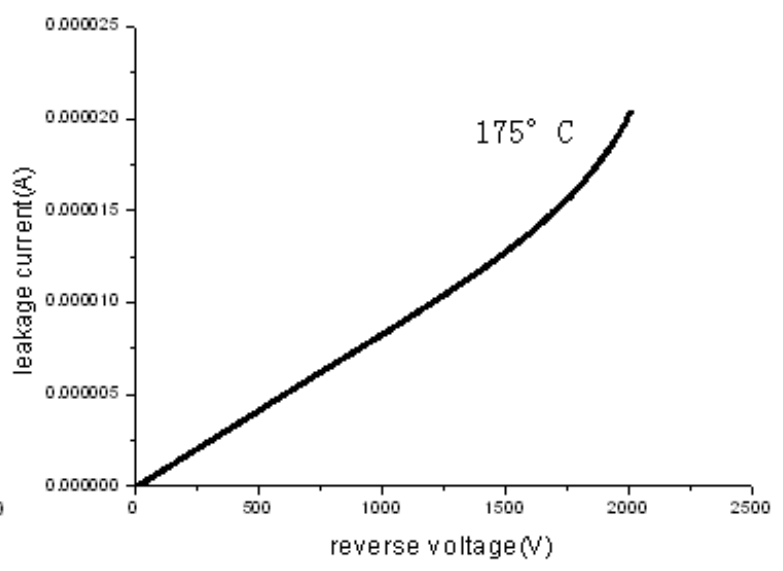

Fig.4 leakage current characteristics of the fabricated module at $175^{\circ} \mathrm{C}$

\section{Forward Characteristics}

The module has been forward characterized in the $25^{\circ} \mathrm{C}$ and $175^{\circ} \mathrm{C}$. Typical forward characteristics are presented in the Fig.5 and Fig.6.

In order to limit the device auto-heating, these characteristics have been obtained in pulse mode 
with a pulse width of $400 \mu \mathrm{s}$. Diodes forward performance has been characterized up to a current density of $300 \mathrm{~A} \cdot \mathrm{cm}^{-2}$ corresponding to $2 \mathrm{~A}$. At $300 \mathrm{~A} \cdot \mathrm{cm}^{-2}$, the voltage drop is $1.4 \mathrm{~V}$ at $25^{\circ} \mathrm{C}$.

The on-state voltage drop increases with temperature, because the Schottky contact barrier lowers. The on-state voltage drop shows a modest increase at the rated current from $1.4 \mathrm{~V}$ at $25^{\circ} \mathrm{C}$ to $1.8 \mathrm{~V}$ at $200^{\circ} \mathrm{C}$.

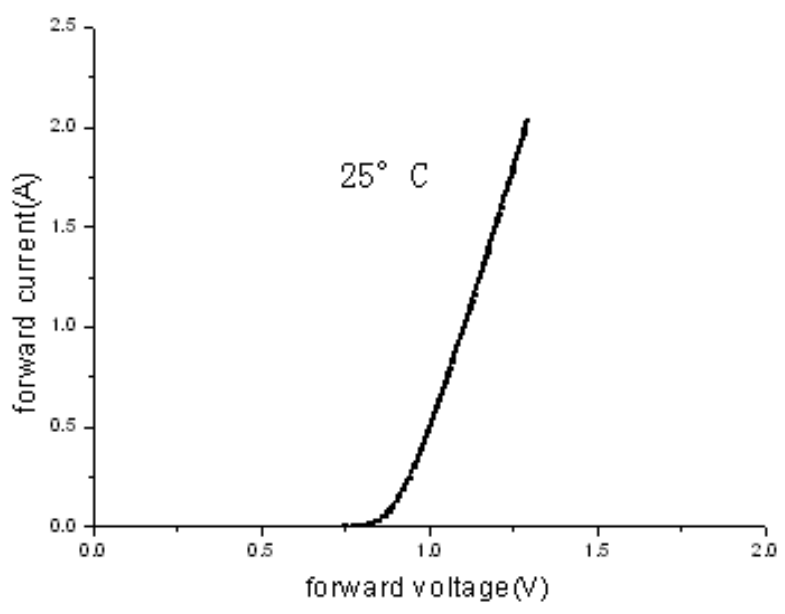

Fig.5 forward characteristics of the fabricated module at $25^{\circ} \mathrm{C}$

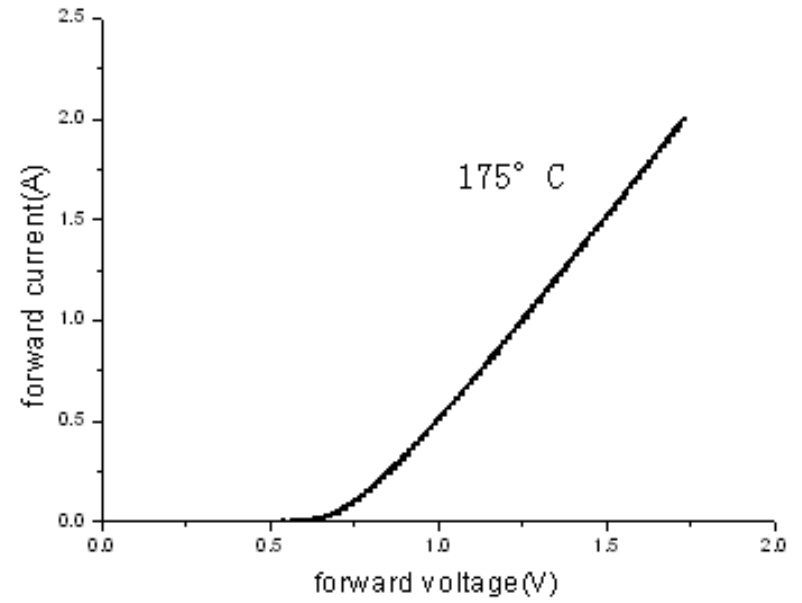

Fig.6 forward characteristics of the fabricated module at $175^{\circ} \mathrm{C}$

\section{Reverse Recovery Characteristics}

Dynamic measurements of the fabricated SiC module have been performed in a double-pulse circuit switched by a SiC MOSFET[4]. The turn-off performance is determined with a current ramp of $\mathrm{di} / \mathrm{dt}=200 \mathrm{~A} / \mathrm{us}$ to a reverse voltage of $1000 \mathrm{~V}$.

Fig.8(a)(b). shows the turn-off waveforms for the fabricated SiC Module, a very low peak reverse recovery current of $1.19 \mathrm{~A}$ is observed, even for switching at $1000 \mathrm{~V}$. Moreover, there is no difference in the switching characteristics at $25^{\circ} \mathrm{C}$ and $175^{\circ} \mathrm{C}$. Recovery time is about $26 \mathrm{~ns}$ and reverse recovered charge is $20 \mathrm{nC}$.

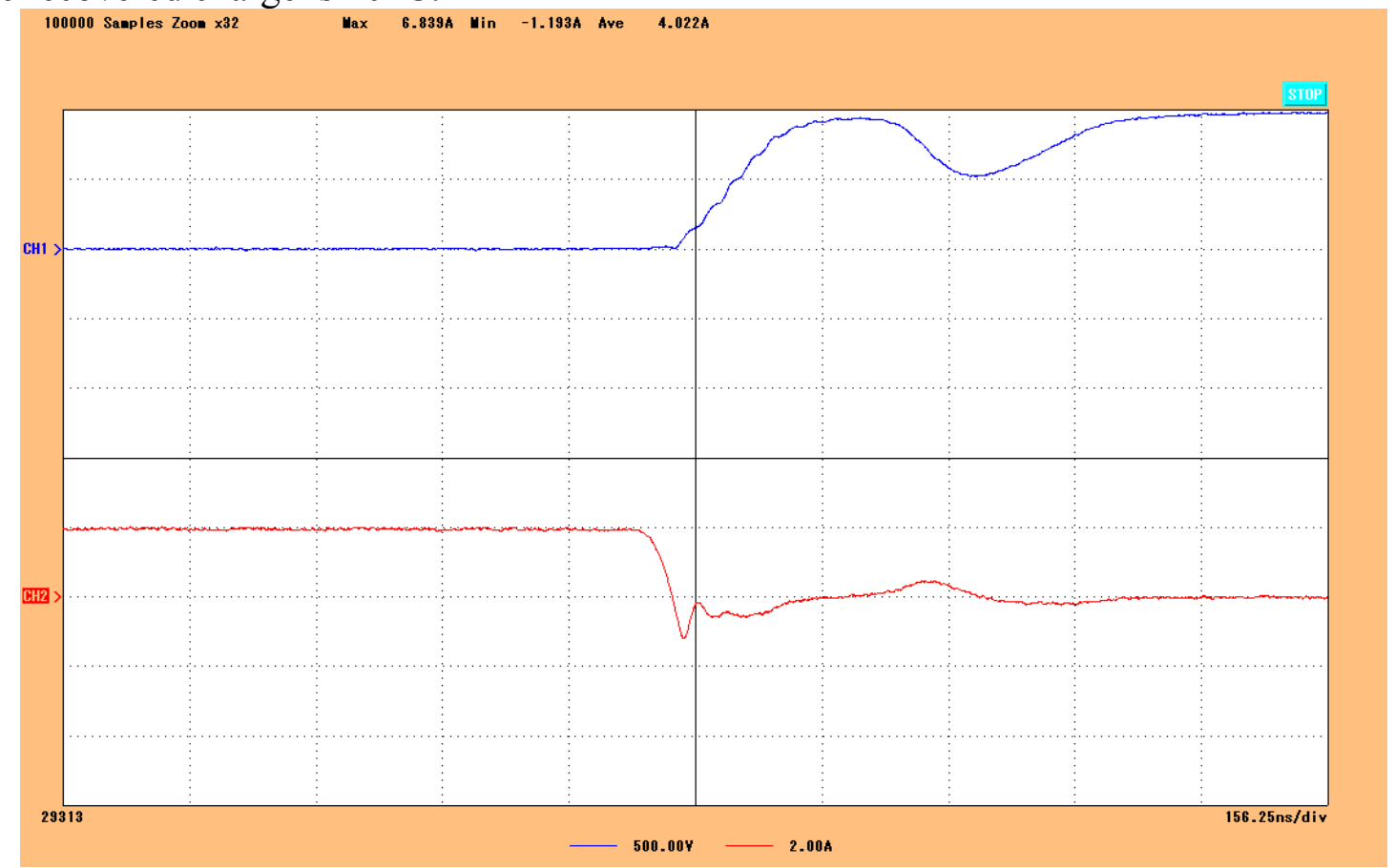

Fig.7 reverse recovery characteristics of the SiC module 


\section{Surge Current Characteristics}

For silicon diode, ability to withstand surge current needs to be evaluated under a large current sine pulse of $8.3 \mathrm{~ms}[5]$. Generally speaking, surge current is six times of rated current. So the $\mathrm{SiC}$ module is evaluated under the same condition. Fig.8 gives the ability of the SiC module to withstand surge current, wave 1 is a $20 \mathrm{~A}$ sine pulse current, wave 2 is the reverse voltage on the module. After a $20 \mathrm{~A}$ current sine pulse flowing through the module, it still obtains capable of blocking more than $2 \mathrm{kV}$.

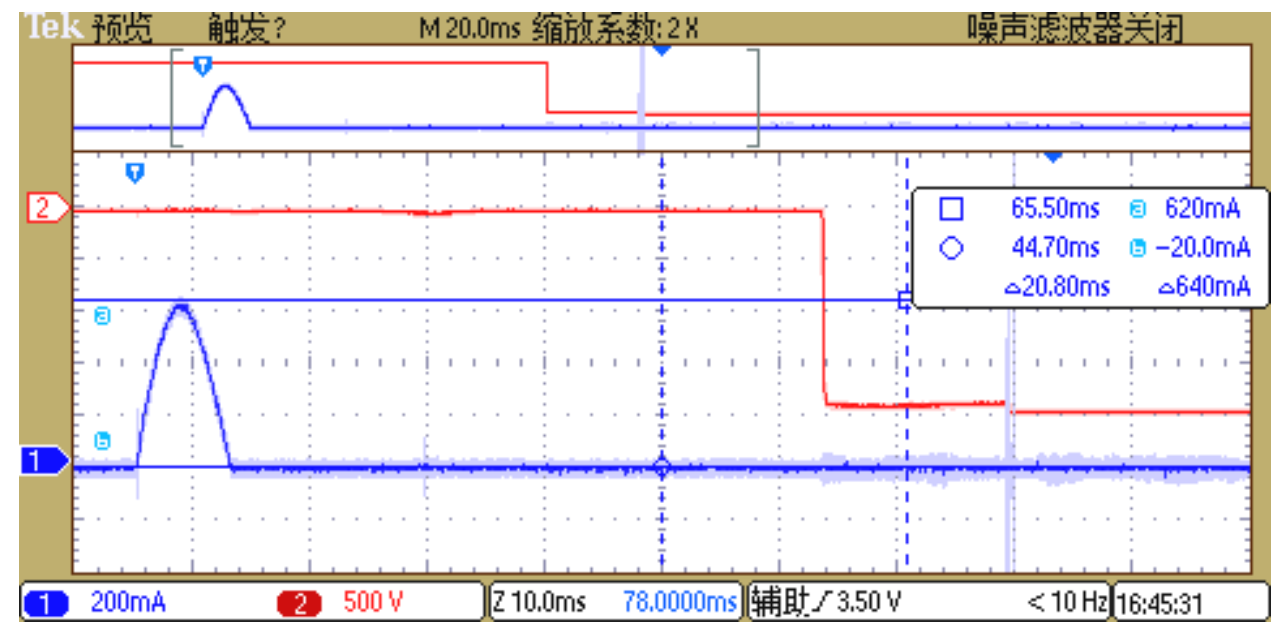

Fig.8 Ability of the SiC module to withstand surge current

\section{Conclusion}

2000V-4A SiC module made up by two 4H-SiC junction barrier schottky (JBS) diodes was designed and fabricated, we achieve good balance between blocking voltage and on-resistance at temperature up to $175^{\circ} \mathrm{C}$. At $175^{\circ} \mathrm{C}$, forward voltage drop is $1.8 \mathrm{~V}$ at current rating of $4 \mathrm{~A}$, and blocking voltage is more than $2 \mathrm{kV}$. Fabricated $4 \mathrm{H}-\mathrm{SiC}$ JBS diodes in the module have superior reverse recovery characteristics. Meanwhile, the module has substantial capacity to withstand surge current.

\section{Acknowledgement}

We would like to thank all the members of wide band gap department and Science and Technology on Monolithic Integrated Circuits and Modules Laboratory.

\section{References}

[1]Chen F P, Zhang Y M, et al. Study of 4H-SiC junction barrier Schottky diode using field guard ring termination[J]. Chin Phys B,2010,19(9):097107

[2]E.Maset, E.Sanchis. Accelerated life test for SiC Schottky Blocking diodes in high temperature environment[J]. IEEE Trans. On Device and Material Reliability, vo19, pp.557-562,2009

[3]Lin Z, Chow T P, Jones K A, et al.Design, fabrication,and characterization of low forward drop,low leakage, 1-kV 4H-SiC JBS rectifiers[J].IEEE Trans Electron Devices,2006,53(2):363

[4]Adamowicz, M. Giziewski, S. Performance comparison of SiC Schottky diodes and silicon ultra fast recovery diodes[C]. CPE 2011. 7th International Conference-Workshop , 2011, 144 - 149

[5] Tone Kiyoshi,Zhao Jian H.,Weiner M.,Pan M.. Fabrication and Testing of 1,000V-60A 4H-SiC MPS Diodes in an Inductive Half-Bridge Circuit[J]. Materials Science Forum . 2000 (338) 